\title{
Resumption of donor-origin spermatogenesis in senescent goldfish Carassius auratus (Linnaeus, 1758) following spermatogonial cell therapy
}

\author{
Sullip K Majhi ${ }^{\text {Corresp., }}{ }^{1}$, Mog Chowdhury ${ }^{1}$, Santosh Kumar ${ }^{1}$, Rajeev K Singh ${ }^{1}$, Vindhya Mohindra ${ }^{1}$, Kuldeep K Lal ${ }^{1}$ \\ 1 National Bureau of Fish Genetic Resources, Lucknow, India \\ Corresponding Author: Sullip K Majhi \\ Email address: skmajhi@nbfgr.res.in
}

Stem cell research has come into prominence because of its applications in assisted reproductive technology and the treatment of deadly diseases. In teleost fishes, spermatogonial stem cells have been effectively used to produce surrogate gametes and progeny through germ cell transplantation technique. The present study is the first report of an innovative application of stem cell therapy in fish species for revitalising the reproductive competence of senescent individuals. Senescent male goldfish, Carassius auratus, approximately 10 years of age were procured from a fish-breeding farm and were reared locally in the lab for an additional two years. The senescence of the individuals was then evaluated and confirmed using histological analysis, gonadal index assessment, and germ-cell specific vasa gene expression. Analyses revealed absence of spermatogonial cells and other germ cells in the testes of the senescent fish $(n=5)$. Spermatogonial cells from sexually immature $C$. auratus male donor were isolated using discontinuous percoll gradients, labelled with the fluorescent dye $\mathrm{PKH}-26$, and transplanted into the gonads of senescent $C$. auratus males through urogenital papilla. Six months after the transplant, spermatozoa were collected through applying gentle manual pressure on the abdomen and were observed under a microscope. All C. auratus males with the transplant had produced spermatozoa from the transplanted cells. This was confirmed by the retention of PKH-26 in the spermatozoa and diagnostic SSR locus. Gravid C. auratus females were artificially inseminated with the spermatozoa of those senescent males and natural spawning was allowed. As a result viable progeny were produced. These observation suggests that the reproductive competence of senescent male fishes can be revitalised through spermatogonial stem cell therapy to produce functional gametes. 
1 Resumption of donor-origin spermatogenesis in senescent goldfish Carassius 2 auratus (Linnaeus, 1758) following spermatogonial cell therapy

3 Short title: Resumption of spermatogenesis in senescent fish

4 Sullip Kumar Majhi*, Labrechai Mog Chowdhury, Santosh Kumar, Rajeev Kumar Singh, 5 Vindhya Mohindra and Kuldeep Kumar Lal 
6

7 Stem cell research has come into prominence because of its applications in assisted reproductive

8 technology and the treatment of deadly diseases. In teleost fishes, spermatogonial stem cells have

9 been effectively used to produce surrogate gametes and progeny through germ cell

transplantation technique. The present study is the first report of an innovative application of stem cell therapy in fish species for revitalising the reproductive competence of senescent individuals. Senescent male goldfish, Carassius auratus, approximately 10 years of age were procured from a fish-breeding farm and were reared locally in the lab for an additional two years. The senescence of the individuals was then evaluated and confirmed using histological analysis, gonadal index assessment, and germ-cell specific vasa gene expression. Analyses revealed absence of spermatogonial cells and other germ cells in the testes of the senescent fish $(n=5)$. Spermatogonial cells from sexually immature $C$. auratus male donor were isolated using discontinuous percoll gradients, labelled with the fluorescent dye PKH-26, and transplanted into the gonads of senescent $C$. auratus males through urogenital papilla. Six months after the transplant, spermatozoa were collected through applying gentle manual pressure on the abdomen and were observed under a microscope. All $C$. auratus males with the transplant had produced spermatozoa from the transplanted cells. This was confirmed by the retention of PKH-26 in the spermatozoa and diagnostic SSR locus. Gravid C. auratus females were artificially inseminated with the spermatozoa of those senescent males and natural spawning was allowed. As a result viable progeny were produced. These observation suggests that the reproductive competence of senescent male fishes can be revitalised through spermatogonial stem cell therapy to produce functional gametes.

\section{Key words: Senescence; Reproduction; Spermatogenesis; Aquaculture; Goldfish}


Introduction

Stem cells are described as undifferentiated cells that have the potential to renew themselves and differentiate into a single cell type or multiple specialised cell types as they can undergo numerous cycles of cell division while maintaining their undifferentiated state (Takeuchi et al. 2004). Currently, stem cell research is one of the upcoming areas of research in science. Since their discovery and the subsequent establishment of protocols for their successful isolation and culture, researchers have used them for various purposes (Zhu et al. 2010), including treatment of chronic diseases and reproductive ailments (Nazari et al. 2015). Stem cell therapy has also shown the potential to revitalise or repair malfunctioning organs by using unscathed donor cells, which can take repair the damaged organ through their potential of differentiation to make the organ function normally and provide animals with an extended and improved life (Min-Wen et al. 2016). In humans, this has opened a new avenue for regenerative medical approaches and has become a viable treatment option in healing chronically damaged organs (Zhao et al. 2014). However, in teleost fish, the use of stem cells for therapeutic purposes 44 has not been explored so far; nevertheless, this therapy has the potential to revitalise malfunctioning reproductive organs of both sexually incompetent or senescent fishes that have a high commercial value or have become critically endangered. Currently, in fish, stem cells are

47 widely used for surrogate brood stock development through germ-cell transplantation (Majhi et al. 2009; Lacerda et al. 2015; Majhi et al. 2014). In this case, the donor cells obtained from young hatchlings or adults are transplanted into the recipient fish at various developmental stages, and on maturation, the recipient fish produce donor-derived gametes (Majhi et al. 2014;

51 Takeuchi et al. 2003). In this study, we demonstrate successful restoration of spermatogenesis in 
52 senescent $C$. auratus through intragonadal stem cell therapy for the first time. The simple

53 approach described in this study ultimately leads to generation of viable functional spermatozoa

54 in senescent $C$. auratus males, which can fertilise eggs derived from young C. auratus females

55 and produce healthy progeny. Thus, this technique extends the reproductive lifespan of the fish

56 beyond the pubertal phase and effectively generates viable progeny.

\section{Materials and Methods}

58 Ethics statement

This study was approved by the Animal Ethics Committee of National Bureau of Fish Genetic Resources (\#G/CPCSEA/IAEC/2015/2).

\section{Animals, age, and rearing protocols}

Male goldfish (C. auratus; $\mathrm{n}=60$; mean body weight \pm standard deviation [SD] of $230 \pm$ $20.5 \mathrm{~g})$ were procured from Maharashtra, India, which were reported to be approximately 10 years old by the providers. The age of the fish was evaluated and confirmed by counting the growth rings located at scale (the growth rings from the fish raised in the farm with known age was used as reference; Supplementary Fig. 1). The fish were stocked in $500 \mathrm{~L}$ tanks after procuring them from the farm at the density of $5.0 \mathrm{~kg}$ of fish per $\mathrm{m}^{3}$ and reared in flow-through fresh water system (temperature: $25{ }^{\circ} \mathrm{C} \pm 2{ }^{\circ} \mathrm{C}$; dissolved oxygen: 5.3-6.1 ppm; $\mathrm{pH}$ : 7.5-8.0; hardness: 40-45 ppm) under a constant light cycle (12 h light and $12 \mathrm{~h}$ dark). The fish were reared for an additional two years before confirmation of their senility through histological analysis and germ-cell-specific vasa gene expression studies. The prepubertal donor C. auratus males (three months old) were produced at the rearing facilities of the National Bureau of Fish Genetic Resources, Lucknow. Both groups of animals were fed a commercially available pelleted diet twice a day to satiation. 


\section{Gonad histology}

After two years of rearing, five fish were randomly sampled and sacrificed using an overdose of anaesthesia (2-phenoxyethanol; HiMedia, India), and their body weights were recorded. The gonads of the fish were excised and weighed, macroscopically examined, and photographed using a digital camera. The middle portion of the right and left gonads from each fish were then immersed in Bouin's fixative for $24 \mathrm{~h}$ and preserved in $70 \%$ ethanol. The gonads were processed for microscopic examination following routine histological procedures up to the stage of preparing 5- $\mu \mathrm{m}$ thick cross-sections and staining them with hematoxylin-eosin. Histological sections from each fish were examined under a microscope at magnifications between $10 \times$ and $60 \times$.

\section{Gene expression analysis}

Samples for real-time reverse transcription polymerase chain reaction (RT-PCR) of vasa gene expression were obtained from the anterior region of the testes after the 2-year rearing period $(n=3)$ and at six months after spermatogonial cell therapy $(n=3)$. The samples were stored in RNAlater (Sigma-Aldrich, St.Louis, MO, USA) at $-80^{\circ} \mathrm{C}$ until further processing. RNA was extracted using TRIzol (Invitrogen Life Technology, Carlsbad, CA, USA) according to the manufacturer's protocol. cDNA was synthesised using a first-strand cDNA synthesis kit (Thermoscientific, USA). The primers for real-time RT-PCR were (5'AACCCTCATGTTCAGCGCCAC-3' and 5'-TGGTTTCAACAAAGACCATCGTGC-3'). The real-time PCRs were run in an ABI PRISM 7300 (Applied Biosystems, USA) system using Power SYBR ${ }^{\circledR}$ Green PCR Master Mix in a total volume of $15 \mu \mathrm{L}$, which included $7.5 \mu \mathrm{L}$ of $2 \times$ Maxima $^{\mathrm{TM}}$ SYBR Green qPCR Master Mix (Thermoscientific, USA), 20 ng of first-strand cDNA and 5 pmol L ${ }^{-1}$ of each primer. $\beta$-actin (5'-GAC TTC GAG CAG GAG ATG G-3' and 5'- 
98 CAA GAA GGA TGG CTG GAA CA-3') was used as an endogenous control. The comparative

$99 \mathrm{Ct}$ method was used for vasa mRNA quantification. The fold change in the expression level was 100 calculated using the $2-\Delta \Delta \mathrm{Ct}$ method (Whelan et al. 2003).

101 Isolation and labelling of donor cells

102 The donor $C$. auratus males $(\mathrm{n}=3)$ were sacrificed using an anaesthetic overdose, and 103 their testes were excised and rinsed in phosphate buffered saline (PBS; $\mathrm{pH}=8.2)$. The testicular 104 tissue was finely minced and incubated in a dissociating solution containing $0.5 \%$ trypsin $(\mathrm{pH}$ 105 8.2; Worthington Biochemical Corp., Lakewood, NJ), 5\% foetal bovine serum (JRH 106 Biosciences, Lenexa, KS), and $1 \mathrm{mmol} \mathrm{L}^{-1} \mathrm{Ca}^{2+}$ in $\mathrm{PBS}(\mathrm{pH} 8.2)$ for $2 \mathrm{~h}$ at $22^{\circ} \mathrm{C}$. The dispersed 107 testicular cells were sieved through a nylon screen (mesh size $50 \mu \mathrm{m}$ ) to eliminate the non108 dissociated cell clumps, suspended in discontinuous percoll (Sigma-Aldrich, St. Louis, MO, 109 USA) gradients of $50 \%, 25 \%$, and $12 \%$ and centrifuged at $200 \times g$ for $20 \mathrm{~min}$ at $20{ }^{\circ} \mathrm{C}$ (Majhi et 110 al. 2014). The bottom phase containing predominantly spermatogonial cells (determined during 111 preliminary trials which involved cell size measurement) was harvested, and the cells were 112 subjected to rinsing as well as a cell viability test through trypan blue $(0.4 \% \mathrm{w} / \mathrm{v})$ exclusion 113 assay. The cells were then exposed to the PKH-26 Cell Linker (Sigma-Aldrich, St.Louis, MO, $114 \mathrm{USA}$ ) at the concentration of $8 \mu \mathrm{mol} / \mathrm{mL}$ (room temperature, $10 \mathrm{~min}$ ) to label the cells for 115 tracking their behaviour inside the senescent (recipient) $C$. auratus gonads. The staining 116 procedure was stopped by the addition of an equal volume of heat-inactivated foetal bovine 117 serum. The labelled cells were rinsed three times to remove the unincorporated dye, suspended in 118 Dulbecco Modified Eagle Medium (Life Technologies, Rockville, MD) with 10\% foetal bovine 119 serum, and placed on ice until transplantation.

\section{Cell therapy procedure}



transplantation platform, where they received a constant flow of oxygenated water containing

$123100 \mathrm{ppm}$ of the anaesthetic drug. To prevent desiccation, the surface of the fish was kept 124 moisturised during the entire procedure of cell transplantation, which lasted for approximately 51257 min per fish on average. A micro syringe was used to inject the cell suspension into the 126 testicular lobe through genital papilla (Supplementary Fig.2). Each fish was injected with $100 \mu \mathrm{L}$ 127 of a cell suspension containing approximately $5 \times 10^{4}$ cells, at the flow rate of approximately 20 $128 \mu \mathrm{L} / \mathrm{min}$. Trypan blue was added to the injection medium prior to transplantation to facilitate 129 visualisation of the cell suspension inside the needle and inside the gonads after injection. The genital papilla region was topically treated with $10 \%$ isodine solution and the fish were returned

131 to clean water.

132

134

\section{Analysis of donor cells post therapy}

The fate of the donor cells after transplantation was analysed through fluorescent microscopy at six and 12 weeks after injection. Then, the testes from the five animals chosen randomly during each sampling were removed, washed in PBS ( $\mathrm{pH}$ 8.2), macroscopically examined for the degree of dispersion of the cell suspension (Fig.1), and immediately frozen in liquid nitrogen. Cryostat (Leica CM 1500, Germany) sections $8 \mu \mathrm{m}$ thick were cut from the representative portions of these testes and observed under a fluorescent microscope (Nikon Eclipse E600, Tokyo, Japan) for detecting the presence of PKH-26-labelled donor cells.

The fate of the donor cells was then examined by measuring the gonado-somatic index $(\mathrm{GSI} ; \mathrm{n}=5)$ and sperm density at six months after therapy. On each occasion, 20-30 $\mu \mathrm{L}$ of sperm was collected from each of the 25 therapy-treated males and five control males. Sperm was manually extracted by applying gentle abdominal pressure after careful removal of urine and 
144 wiping the genital papilla. The sperm samples $(10 \mu \mathrm{L})$ were then diluted 1,000 times with PBS 145 and the density of spermatozoa was counted using a haemocytometer (Marienfeld, Germany) 146 under a microscope. Some of the spreads of sperm used for counting were also observed under 147 the fluorescent microscope for the detection of PKH-26-labelled cells.

148 Sperm and blood samples were collected at 18 months from the spermatogonia cell 149 transplanted senescent male $(n=25)$. Total DNA was extracted using PureLink Genomic DNA kit 150 (Invitrogen Life Technology, Carlsbad, CA, USA) according to the manufacturer's protocol and DNA typing was done using $C$. auratus SSR locus J60* (forward 5'CTGGCTGTCTGATCCTGCTGAT-3' and reverse $5^{\prime}-$

153

154

155

156

TGGCCAGAGTtTAAAAACCAGTCC-3') (Yue and Orban 2002). PCR reaction was performed in $25 \mu \mathrm{L}$ consisted of $1 \mathrm{x}$ Taq buffer, $1.5 \mathrm{mM} \mathrm{MgCl}_{2}, 0.5 \mu \mathrm{m}$ each primer, $200 \mu \mathrm{M}$ of dNTP, $0.75 \mathrm{U}$ Taq DNA polymerase and $80 \mathrm{ng}$ of the DNA template. The amplification was done in a thermal Cycler (ThermoFisher Scientific, USA) and consisted of an initial denaturation at $94{ }^{\circ} \mathrm{C}$ for $5 \mathrm{~min}, 25$ cycles of $94{ }^{\circ} \mathrm{C}$ for $30 \mathrm{sec}, 62{ }^{\circ} \mathrm{C}$ for $30 \mathrm{sec}$ and $72{ }^{\circ} \mathrm{C}$ for $30 \mathrm{sec}$, followed by elongation at $72{ }^{\circ} \mathrm{C}$ for $4 \mathrm{~min}$. Amplified products was visualized by $10 \%$ polyacrylamide gel electrophoresis (PAGE) and silver staining. Amplicon sizing was done on gel imaging and analysis system (UVP) using Msp I digested pBR322 as ladder.

\section{Artificial fertilization and induced spawning}

After 6 months, the senescent therapy-treated $C$. auratus males $(\mathrm{n}=25)$ resumed production of spermatozoa. Artificial insemination and natural spawning were performed using eggs from wild $C$. auratus females. Approximately $20 \mu \mathrm{L}$ of milt from each of the ten therapytreated males was used to fertilise a batch of $C$. auratus eggs. The batches of eggs were then incubated under flowing water at $25{ }^{\circ} \mathrm{C}$ until hatching. In the natural spawning trials, ten 
167 senescent therapy-treated males and wild females were paired in a $100 \mathrm{~L}$ glass aquarium and

168 reared in fresh water (Temperature: $25^{\circ} \mathrm{C} \pm 2{ }^{\circ} \mathrm{C}$; dissolved oxygen: 5.3-6.1 ppm; pH: 7.5-8.0;

169 hardness: 40-45 ppm) under a constant light cycle (12 h light and $12 \mathrm{~h}$ darkness). Every,

170 morning between 10:00 and 11:00 h, the tanks were examined for spawning and embryos were

171 collected. The fertilised eggs obtained from each cross were incubated at $25^{\circ} \mathrm{C}$ and observed

172 under a light microscope for the assessment of fertilisation, embryonic development, and 173 hatching.

\section{Statistical analysis}

175 The statistical significance of the differences in vasa gene expression levels, GSI values and sperm densities among the groups is evaluated using one-way analysis of variance and

177 Tukey’s multiple comparison test. Graphpad Prism ver. 4.00 (Graphpad Software, San Diego,

178 Carlifornia, USA) is used for statistical analyses. Data are presented as mean \pm SD and the 179 differences among the groups are considered as statistically significant at $p<0.05$.

180

181

182

183

184

185

186

187

188

\section{Results}

\section{Histological observation of germ cells}

Microscopic examination of the testes revealed that all the five senescent $C$. auratus males aged 12 years exhibited shrunken gonads (Fig. 1A) and complete disappearance of all the stages of germ cells (Fig. 2A-B) in all sections examined before stem cell transplantation. By contrast, the control males (age $>1$ year) exhibited active spermatogenesis with a large cyst of spermatogonial cells, all stages of germ cells (Fig. 2C-D) and their efferent duct contained spermatozoa. These histological observations were also corroborated by the results of GSI evaluation and real-time RT-PCR analysis, which showed that both GSI (Fig. 3) values and vasa 
189 gene transcript levels (Fig. 4) were significantly lower in the senescent males compared to the 190 controls $(p<0.05)$

\section{Fate of transplanted cells in senescent testes}

The transplanted donor spermatogonial cells were found randomly distributed throughout

193

194

195

196

197

198

199

200

201

202

203

204

205

206

207

208

209

210

211 the spermatogenic lobules in all the five senescent males examined 6 weeks after the therapy. At

12 weeks after the therapy, the donor spermatogonial stem cells had reached the blind end of the lobules (cortical region of the testis; Fig. 5A-D) and had undergone proliferation to form a network along the testicular lobule; this stage was observed in all the sampled fish (n=5; Fig. 5E). At six months after the therapy, the sperm could be collected by applying gentle pressure on the abdomen of all 25 senescent $C$. auratus males (Fig. 5F). The sperm density, which was not detectable before the therapy, had significantly increased after the therapy and was comparable with that of the reproductive control males (Fig. 6).

\section{Production of viable gametes and progeny from senescent males}

Six months after cell therapy, the senescent $C$. auratus males resumed spermatogenesis and produced spermatozoa from the transplanted cells; the origin of the spermatozoa (from the transplanted cells) was confirmed by the existence of two different genotypes and presence of the red fluorescent labels in the cells (Fig. 5F). Locus $J 60^{*}$ differentiated amplicons from blood (recipient) and sperm (donor cell) DNA (Fig. $7 \& 8$ ). These therapy-treated males were then used for artificial fertilization and for trials of induced spawning of eggs obtained from young $C$. auratus females (Tables 1-2). These crosses resulted in normal embryonic development and hatching, which were similar to those in the control fish. Breeding between the spermatozoa from therapy-treated males and eggs from wild C. auratus females resulted in $88.6 \%-97.5 \%$ hatching whereas $93.8 \%-97.7 \%$ result was obtained in the control (Table 1).On the other hand,

Peer) reviewing PDF | (2019:11:42837:2:0:NEW 3 Apr 2020) 
212 when the senescent males were coupled with wild $C$. auratus females for induced spawning, the

213 breeding resulted in 95.5\%-99.5\% hatching with normal embryonic development and viable

214 progeny; oppose to $97.7 \%-98.4 \%$ in control (Table 2). These observations suggest the viability

215 of the proposed approach in revitalising the reproductive competence of the males from

216 commercially valuable fish species that have aged and can no more impregnate the females.

\section{Discussion}

In the present study, spermatogonial cells harvested from prepubertal $C$. auratus testes were successfully transplanted for restoring the reproductive competence of senescent C. auratus males by using cell-therapy. As observed in mammals (Brinster and Zimmermann 1994; Ogawa et al. 1999), the therapy resulted in recolonization of the seminiferous epithelium, resumption of spermatogenesis, and production of functional spermatozoa. The simple but effective procedure demonstrated in this study can be immediately applied in hatcheries and other seed production facilities. This procedure has a considerable potential for extending the reproductive phase of commercially valuable species.

The testes recovered from the senescent $C$. auratus males exhibited shrinkage of testicular lobes, absence of germ cells, and deposition of adipose and connective tissue. The germinal epithelium was continuous, and the testicular cross-section was noticeably smaller than that observed in reproductive males. Notably, this observation is contrary to that in senescent guppy (Lepistes reticulatus) in which histological changes in the testes revealed a progressive increase in the percentage of lobules containing spermatids and spermatozoa and an increase in

232 the deposition of melanin as well as adipose and connective tissue (Woodhead and Elett 1969). However, in senescent mosquito fish (Gambusia affinis) and European bitterling (Rhodeus amarus), partial testicular degeneration was observed to occur with a considerable reduction in 
235 the number of germ cells (Woodhead 1979; Rasquin and Hafter 1951; Haranghy et al. 1977).

236 According to Finch (1990) such variations in the gonadal germ cell profiles and testicular

237 morphologies of senescent fishes are due to their growth patterns and origins of habitation. Thus,

238 the characteristics of senescence in fishes cannot be generalised and vary widely depending on

239 their habitation history and other physico-chemical parameters of their ecosystem (Liu and

240 Walford 1966). For instance, tropical fish species grow faster and attain senescence

241 comparatively earlier than do temperate fish species (Patnaik et al. 1994). The experimental fish

242 used in this study were reared in a tropical environment (temperature range: $25^{\circ} \mathrm{C}-32{ }^{\circ} \mathrm{C}$ ) for 10

243 years; probably this may explain why germ cell degeneration in the senescent individuals was

244 considerably more severe than that previously reported in other fish species.

245 Regardless of the differences between sterile (natural or experimentally induced) and

246 senescent testes, the process of recolonization by the transplanted spermatogonial cells was

247 similar to the previously reported process (Majhi et al. 2009; Lacerda et al. 2015; Majhi et al.

248 2014; Ogawa et al. 2000). For instance, after cell therapy, many PKH-26-labelled

249 spermatogonial cells eventually settled along the blind end of the seminiferous lobules and began

250 proliferation within weeks of transplantation. Considering that only spermatogonial stem cells

251 can migrate and settle at the basement membrane and resume the process of spermatogenesis

252 (Ogawa 2001), we can surmise that the cells used for therapy were spermatogonial stem cells.

253 This conclusion is also proved by the fact that when the senescent $C$. auratus males (26 months

254 after cell therapy) were repeatedly paired with wild $C$. auratus females for natural spawning,

255 they continued to produce viable progeny to date. Transmembrane protein molecules present at

256 the junctional complex located in the seminiferous tubules have been reported to transduce

257 signals, maintain cell polarity, and mediate germ cell migration (Wang and Cheng 2007). 
258 Although we did not examine the endocrine regulation involved in the migration, proliferation

259 and differentiation of the donor spermatogonial cells inside the gonads of senescent $C$. auratus 260 males, the results obtained in the present study (time-course observations of donor 261 spermatogonial cells after therapy) indicated that the donor spermatogonial cells might have 262 sensed and responded to the molecules released from the blind end of the seminiferous lobules in 263 therapy-treated senescent $C$. auratus males. Consequently, these spermatogonial cells migrated 264 and settled down near the basement membrane and resumed spermatogenesis. However, the 265 duration for which the $C$. auratus males treated with spermatogonial cell therapy retain their 266 reproductive competence and produce functional gametes remains to be determined. The present study demonstrated that spermatozoa derived from therapy-treated senescent C. auratus males exhibited functional properties similar to those of the control spermatozoa in terms of fertilisation, embryonic development and hatching, and no evidence of defective spermatozoa was observed. Defective spermatogeneis has been reported to occur most prominently when the donor and recipient animals are phylogenetically distant (Nantel et al. 1996). In this study, the spermatogonial cells derived from pre-pubertal C. auratus males were

273 transplanted into senescent $C$. auratus males; thus, the transplanted cells were probably immunologically compatible with the gonadal environment of the senescent $C$. auratus males. Moreover, the progeny produced using the spermatozoa derived from therapy-treated C. auratus males exhibited a similar growth pattern to that of the progeny produced from the control males.

277 These observations suggest that the reproductive competence of senescent $C$. auratus males could be successfully revitalised using spermatogonial cell therapy. Currently, we are examining

279 the feasibility of the cell-therapy approach in revitalising the reproductive competence of female 280 C. auratus. 
functional spermatozoa from senescent $C$. auratus males after spermatogonial cells derived from

the pre-pubertal $C$. auratus donor were transplanted into the testes of the senescent males through the genital papilla. This approach, which to the best of our knowledge has been validated

287 breeding of rare and/or commercially valuable fish species that are developed as brooders and

a few years by the hatcheries for seed production and are invariably discarded when they lose their reproductive competence because of age.

\section{Acknowledgements}

The authors express sincere thanks to the Director, NBFGR, Lucknow for providing all necessary help to perform this work.

294 Competing interests: The authors confirm that there are no known conflicts of interests to 295 declare and there has been no significant financial support for this research.

\section{References:}

297 Brinster RL, Zimmermann JW. 1994. Spermatogenesis following male germ-cell transplantation. Proc. Natl. Acad. Sci. U.S.A. 91:11298-11302

299 Finch CE. 1990. Senescence and the genome. Chicago, University of Chicago press. 75-107

300 Haranghy L, Penzes L, Kerenyi T, Penzea B. 1977. Sexual activity and aging in the teleost fish, 301 Rhodeus serviceus amarus. Experimental Gerontology 12:17-25 
302 Lacerda SMSN, Batlouni SR, Costa GMJ, Segatelli TM, Quirino BR, Queiroz BM, Kalapothakis

303 E, França LR. 2015. A new and fast technique to generate offspring after germ cells

304 transplantation in adult fish: the Nile tilapia (Oreochromis niloticus) model. PLOS ONE

305 5:e10740

306 Liu RK, Walford RL. 1966. Increased growth and lifespan with lowered ambient temperature in

307 the annual fish Cynolebias adloffi. Nature 212:1277-1278

308 Majhi SK, Hattori RS, Rahman SM, Strüssmann CA. 2014. Surrogate production of eggs and 309 sperm by intrapapillary transplantation of germ cells in cytoablated adult fish. PLOS ONE 310 9:e95294

311 Majhi SK, Hattori RS, Yokota M, Watanabe S, Strüssmann CA. 2009. Germ cell transplantation

312 using sexually competent fish: an approach for rapid propagation of endangered and valuable 313 germlines. PLOS ONE 4:e6132

314 Min-Wen JC, Jun-Hao ET, Shyh-Chang N. 2016. Stem cell mitochondria during aging. Seminars 315 in Cell \& Developmental Biology 52:110-118

316 Nantel F, Monaco L, Foulkes NS, Masquilier D, LeMeur M, Henriksén K, Dierich A, Parvinen 317 M, Sassone-Corsi P. 1996. Spermiogenesis deficiency and germ-cell apoptosis in CREM 318 mutant mice. Nature 380:159-162

319 Nazari H, Zhang L, Zhu D, Chader GJ, Falabella P, Stefanini F, Rowland T, Clegg DO, Kashani 320 AH, Hinton DR, Humayun MS. 2015. Stem cell based therapies for age- related macular 321 degeneration: The promises and the challenges. Progress in Retinal and Eye Research $322 \quad 48: 1 \mathrm{e} 39$

323 Ogawa T, Dobrinski I, Avarbock MR, Brinster RL. 2000. Transplantation of male germ line 324 stem cells restores fertility in infertile mice. Nat. Med. 6:29-34 
325 Ogawa T, Dobrinski R, Brinster RL. 1999. Recipient preparation is critical for spermatogonial 326 transplantation in the rat. Tissue Cell 31:461-472

327 Ogawa T (2001) Spermatogonial transplantation: the principle and possible application. J. Mol. 328 Med. 79:368-374

329 Patnaik BK, Mahapatro N, Jena BS. 1994. Ageing in fishes. Gerontology 40:113-132

330 Rasquin R, Hafter E. 1951. Age changes in the testis of the teleost, Astyanax americanus. 331 Journal of Morphology 89:397-404

332 Takeuchi Y, Yoshizaki G, Takeuchi T. 2003. Generation of live fry from intraperitoneally 333 transplanted primordial germ cells in rainbow trout. Biol. Reprod. 69:1142-1149

334 Takeuchi Y, Yoshizaki G, Takeuchi T. 2004. Surrogate broodstock produces salmonids. Nature 335 430:629

336 Wang CQF, Cheng CY. 2007. A seamless trespass: germ cell migration across the seminiferous 337 epithelium during spermatogenesis. Journal of Cell Biology 178:549- 556

338 Whelan JA, Russell NB, Whelan MA. 2003. A method for absolute quantification of cDNA 339 using real-time PCR. Journal of Immunological Methods 278:261-269

340 Woodhead AD. 1979. Senescence in fishes. Symp. Zool. Soc. London 44:179-205

341 Woodhead AD, Elett S. 1969. Endocrine aspects of aging in the guppy, Lepistes reticulatus 342 (Peters). III. Testis. Experimental Gerontology 4:17-25

343 Yue GH, Orban L. 2002. Polymorphic microsatellites from silver crucian carp (Carassius 344 auratus gibelio Bloch) and cross-amplification in common carp (Cyprinus carpio L.). Molecular 345 Ecology Notes 2:534-536 
346 Zhao L, Borikova AL, Ben-Yair R, Guner-Ataman B, MacRae CA, Lee RT, Burns CG, Burns

347 CE. 2014. Notch signaling regulates cardiomyocyte proliferation during zebrafish heart

348 regeneration. Proc. Natl. Acad. Sci. U. S. A. 111:1403-1408

349 Zhu H, Guo Z, Jiang X, Li H, Wang X, Yao H, Zhang Y, Mao N. 2010. A protocol for isolation

350 and culture of mesenchymal stem cells from mouse compact bone. Nature Protocols 5:550-560 


\section{Figure 1}

Visualization of the dispersal of the cell suspension through the gonad of senescence $C$. auratus after transplantation.
A) Macroscopic appearance of the testis 48 hours after spermatogonia cell transplantation (note the diffusion of the marker Trypan blue throughout the testis). B) Appearance of the testis 6 months after cell transplantation (note the transplanted cells in senescence testis have undergone proliferation and differentiation to match the testis of a sexually mature individual). Scale bars indicate $2 \mathrm{~cm}$. 

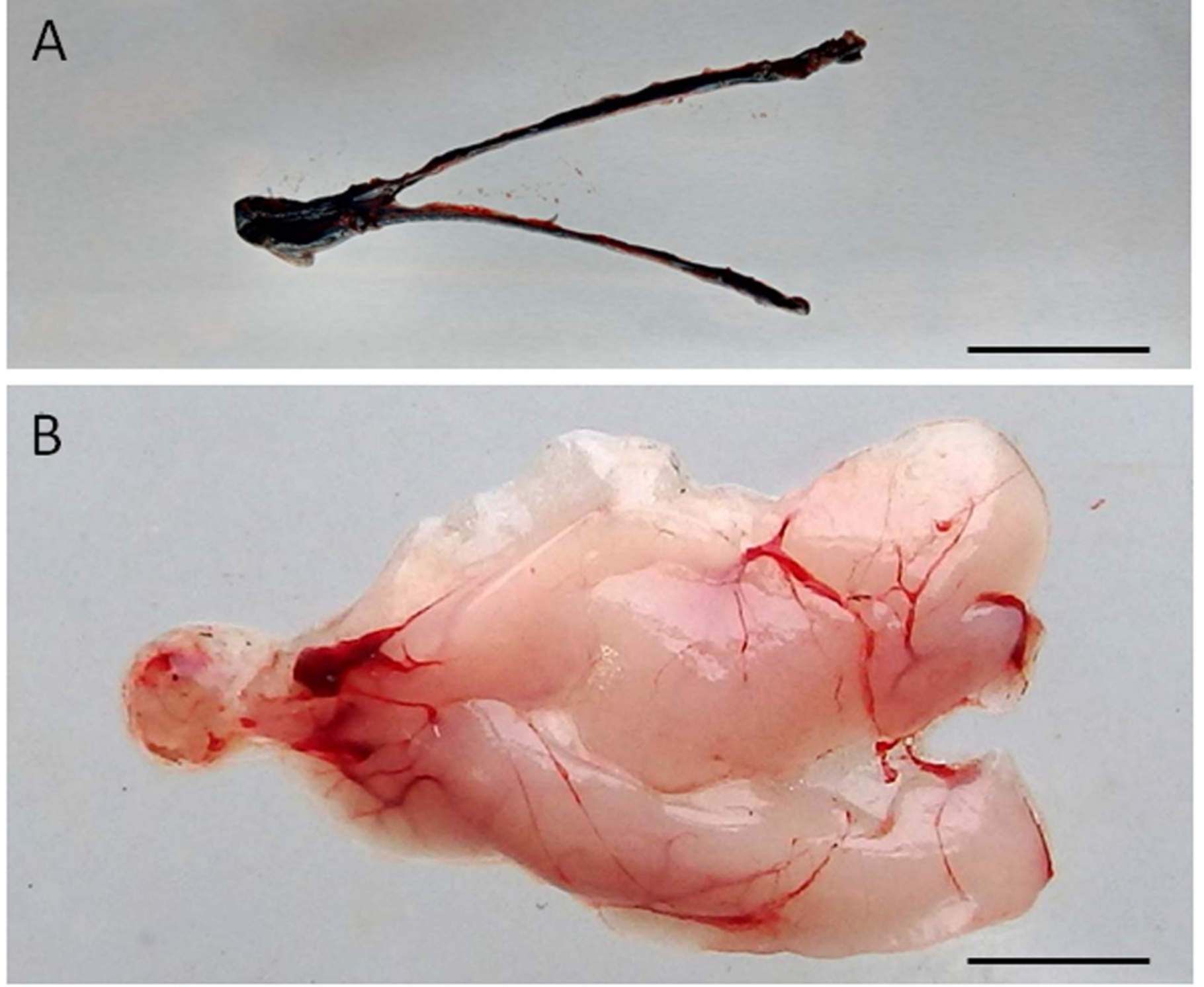


\section{Figure 2}

Histological appearance of senescence and control C. auratus gonads

Panels on the right are high magnifications of insets in the left panels. A,B) Twelve year old senescence testis showing empty niche (arrows) with complete absence of spermatogonia and other germ cells. C,D) A sexually mature control testis indicating large cysts of spermatogonia in the blind end of the spermatogenic lobules (arrows), spermatocytes (arrowhead) and spermatids (star) depicting an active spermatogenesis within the lobules. Scale bars indicate $100 \mu \mathrm{m}$ ( $A$ and $C$ ) and $20 \mu \mathrm{m}$ (B and D).
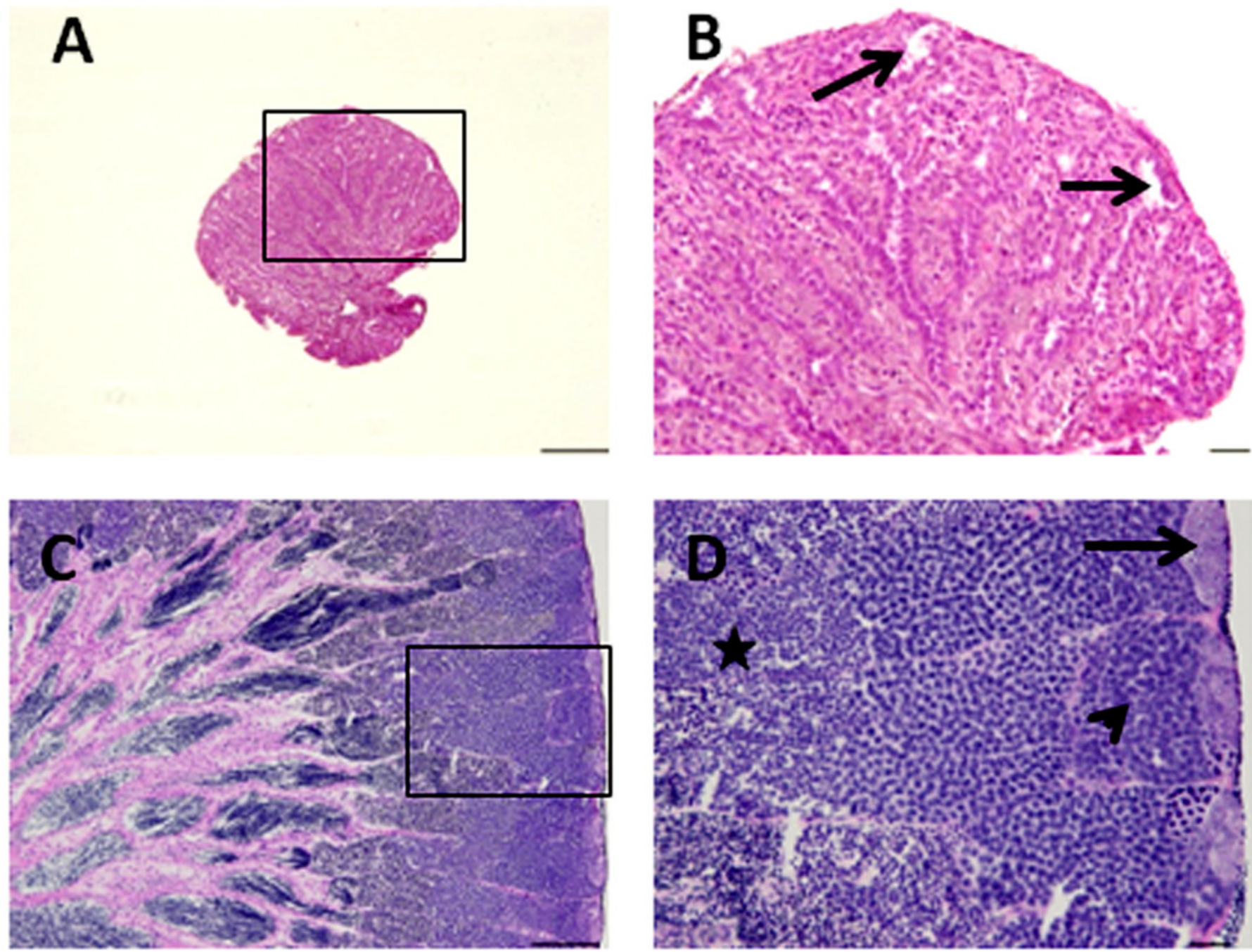


\section{Figure 3}

Changes in the gonado-somatic index of senescence and control gonads between 0 day (A) and six months (B).

Note, six months after therapy the gonado-somatic index value of senescence $C$. auratus males have significantly increased to match the sexually mature control. Data are presented as mean \pm SD. Columns with double asterisk vary significantly (ANOVA - Tukey test, $p<0.05$ ).

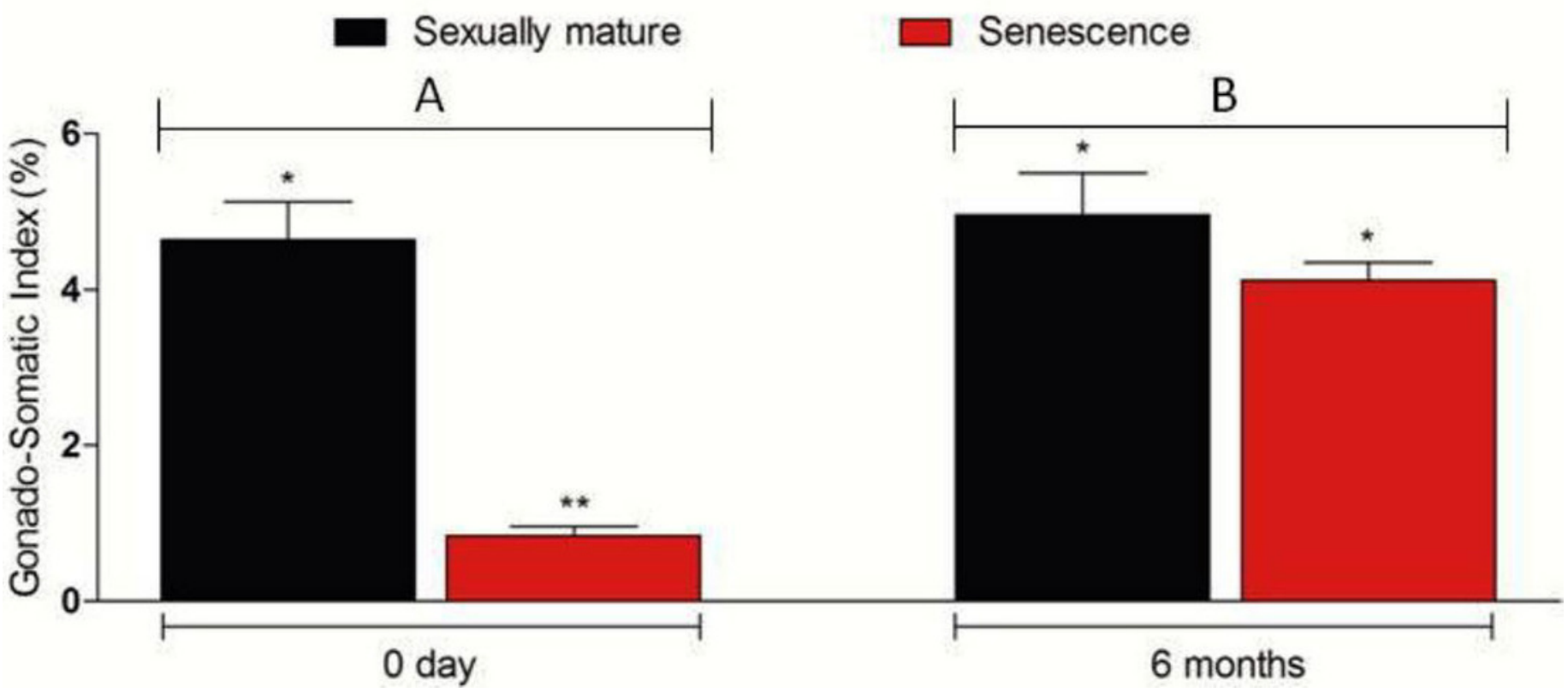


Figure 4

Changes in vasa gene transcript levels in senescence and control $C$. auratus gonads between 0 day $(A)$ and six months $(B)$.

Note, six months after therapy the vasa gene transcript levels in senescence $C$. auratus males have significantly increased to match the reproductive control. Data are presented as mean \pm SE. Columns with double asterisk vary significantly (ANOVA - Tukey test, $p<0.05$ ).

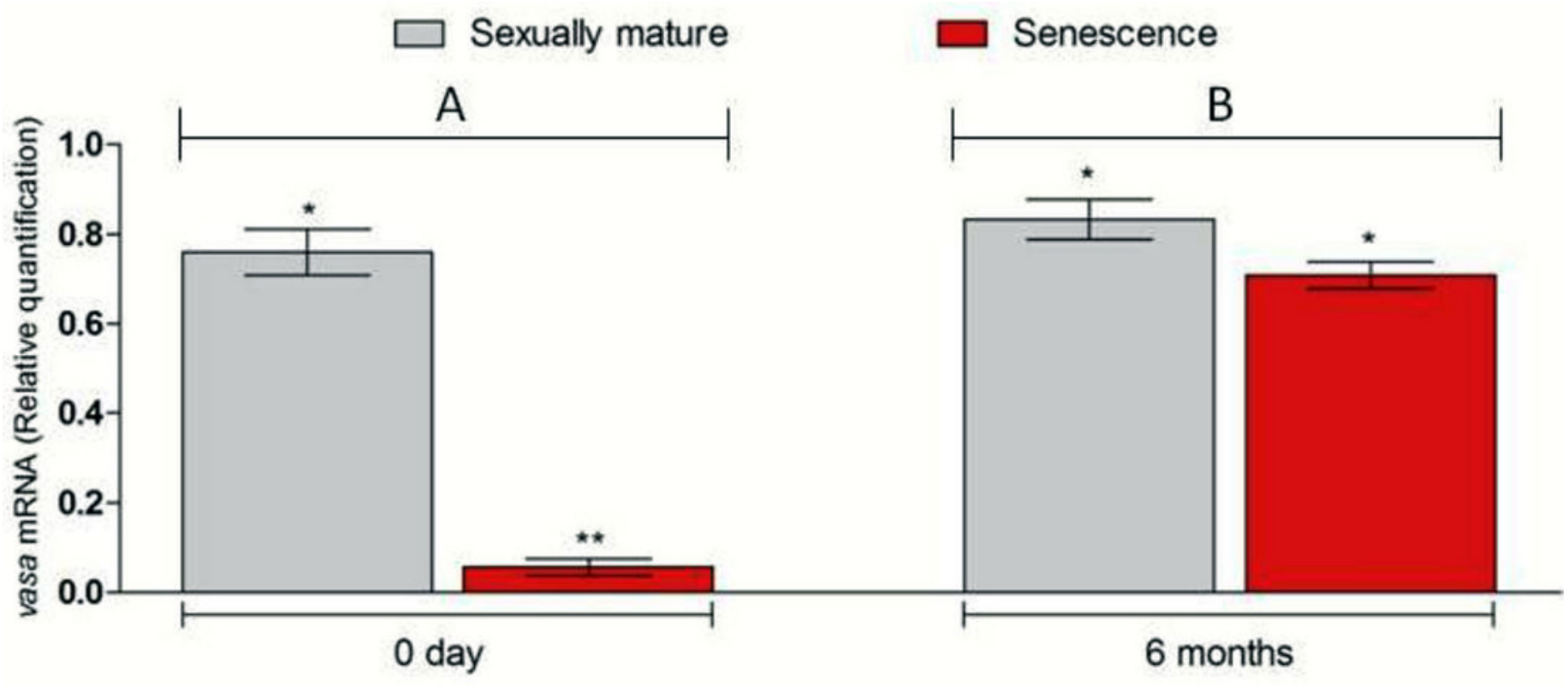




\section{Figure 5}

Fate of PKH-26-labeled donor spermatogonia cells in senescent $C$. auratus males examined between four weeks and six months after transplantation.

$A, B)$ Cryostat section of a transplanted testis at four weeks showing the presence of transplanted spermatogonia cell at the blind end of the spermatogenic lobules (arrow; B is a high magnification of the box in A). C,D) Cryostat section of a non-transplanted, control testis at four weeks showing the approximate location of the blind end of the spermatogenic lobules ( $D$ is a high magnification of the box in $C$ ). E) Whole-mount preparation of a transplanted testis at twelve weeks showing the proliferation of donor-derived cells (highlighted) along the length of the gonad. F) Whole-mount preparation of spermatozoa cell derived from the senescent male 6 months after the procedure (Note, the spermatozoa produced were of donor-origin that was characterized by retention of PKH-26 dye). Scale bars indicate $100 \mu \mathrm{m}$ ( $A$ and $C$ ), $20 \mu \mathrm{m}$ ( $B$ and $D), 500 \mu \mathrm{m}(E)$ and $50 \mu \mathrm{m}(F)$. 

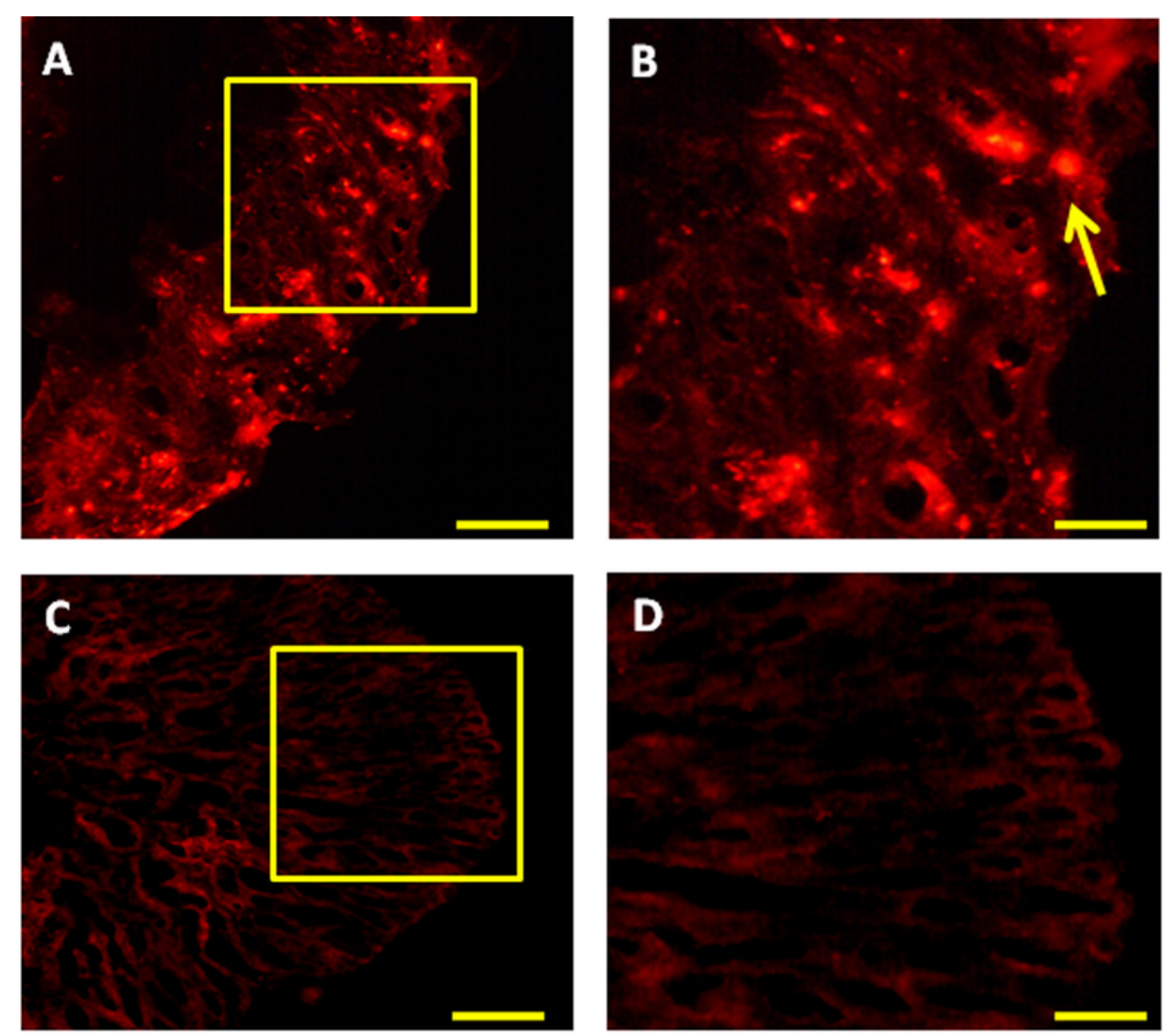

D

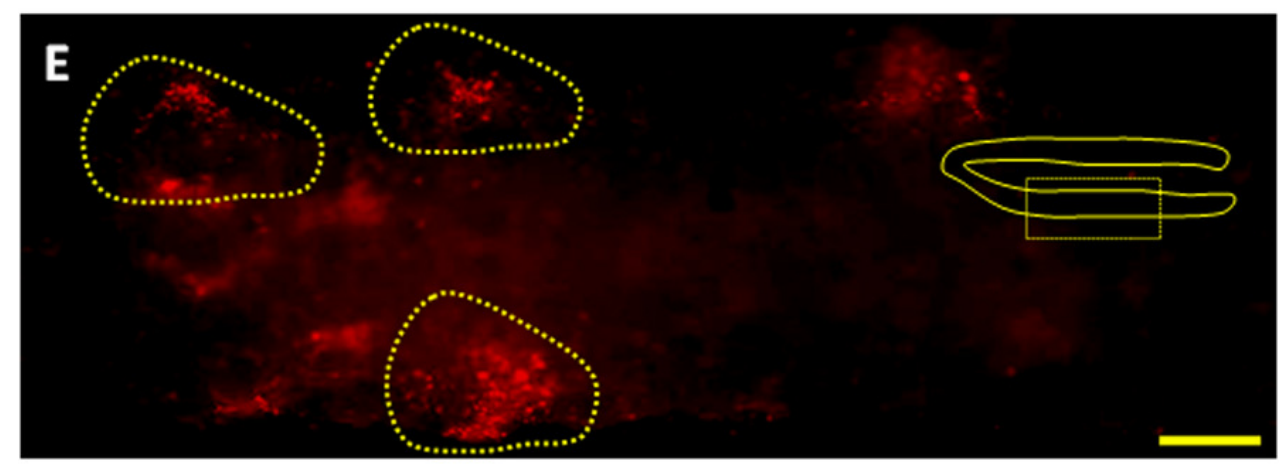

F

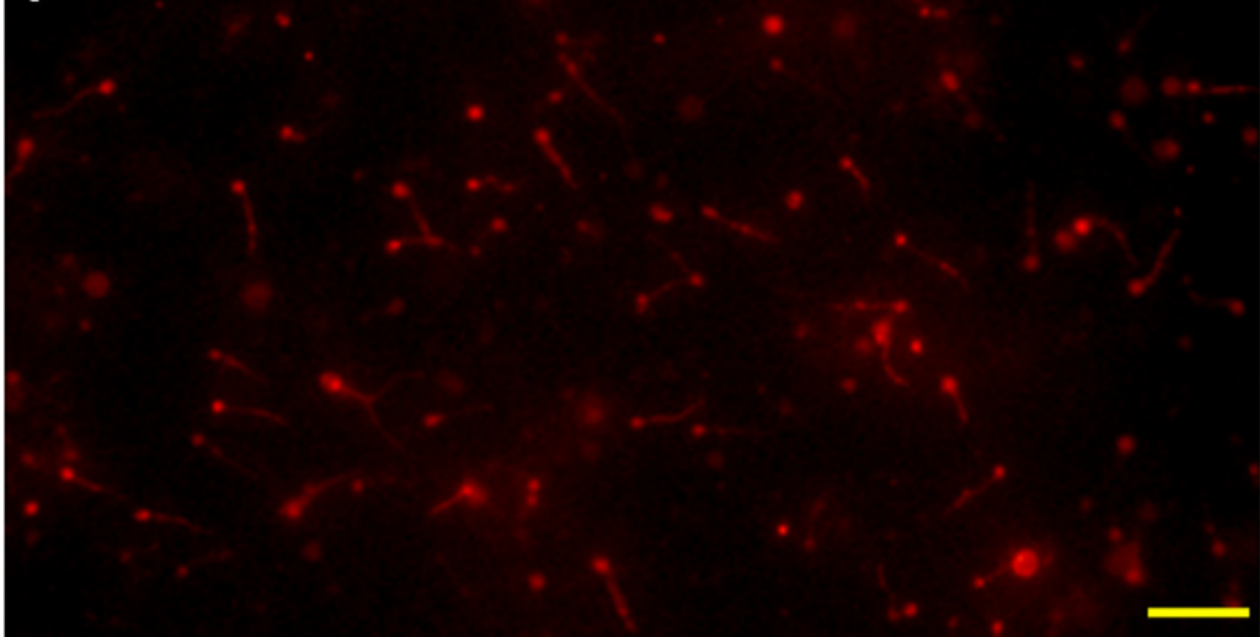

Peer) reviewing PDF | (2019:11:42837:2:0:NEW 3 Apr 2020) 


\section{Figure 6}

Sperm density in senescent recipients and non-transplanted (negative control) $C$. auratus between 0 day $(A)$ and 6 months (B) after spermatogonial cell therapy.

Note, the sperm count in the senescent males had significantly increased after spermatogonial cell therapy. Data are presented as mean \pm SD. Columns with double asterisk vary significantly (Tukey's multiple comparison test, $p<0.05$ ).

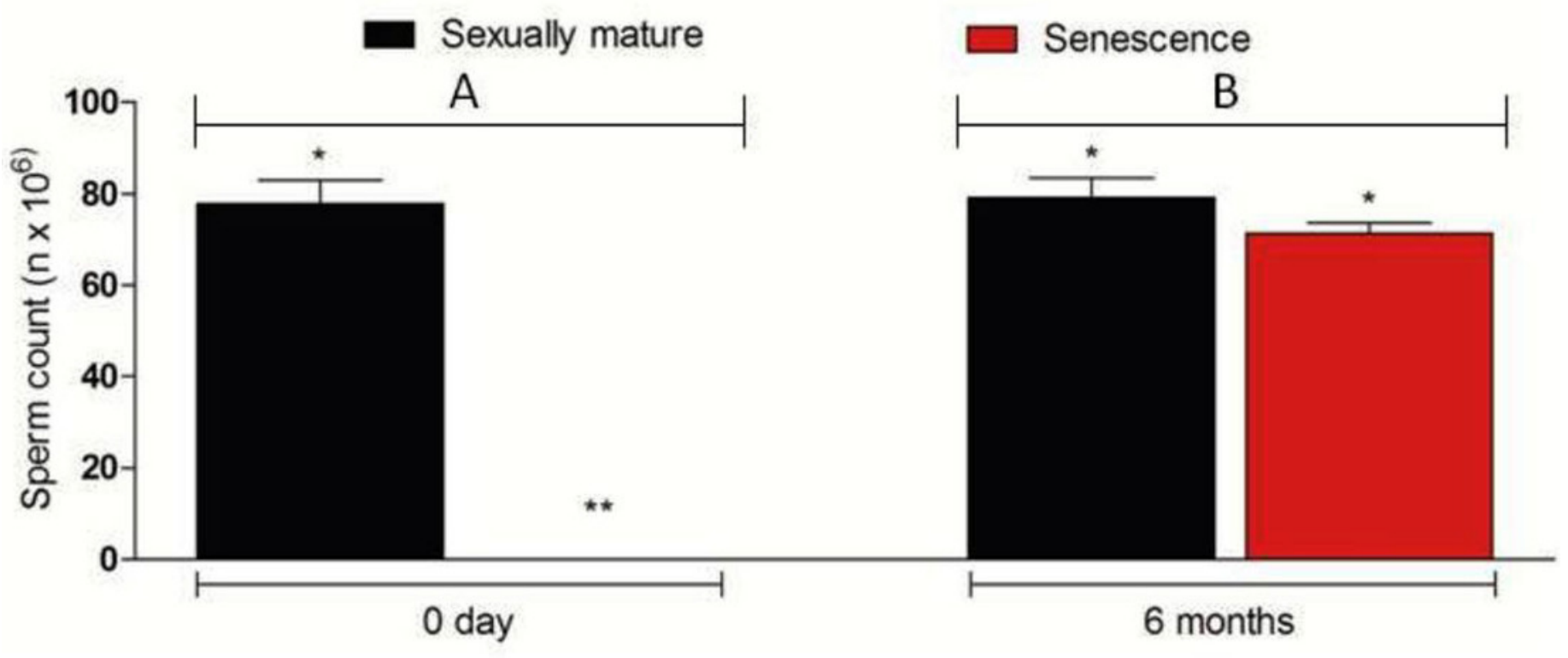




\section{Figure 7}

Genotyping of sperm and blood collected from a senescent $C$. auratus males 18 months after the cell transplantation.
A) The senescent $C$. auratus male used in the experiment. B) The donor spermatogonial cell transplantation in senescent $C$. auratus male. C) Collection of sperm and blood samples from senescent $C$. auratus males 18 months after the cell transplantation. D) DNA isolation from the samples using PureLink Genomic DNA kit according to the manufacturer's protocol. E) The microsatellite primers were used for amplification of DNA for genotyping. F) Lanes include molecular marker (M), blood of senescent male (1) and sperm (2). Note, the donor- derived spermatozoa were detected in the sperm of senescent recipient shown in lane 2. 
A

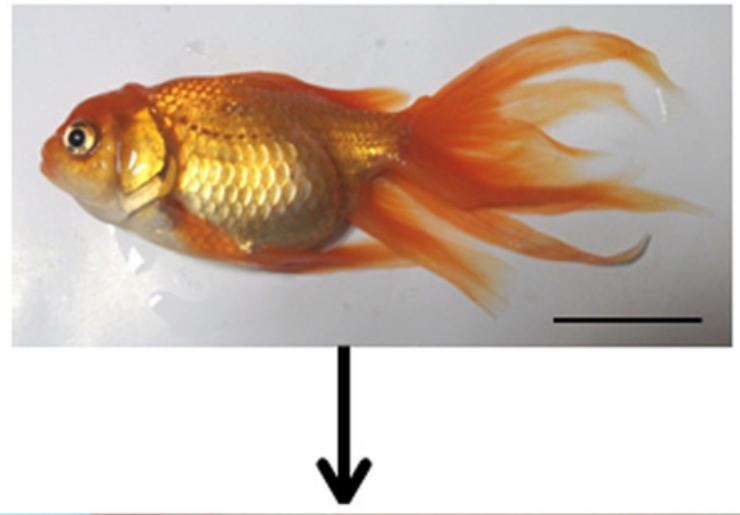

B

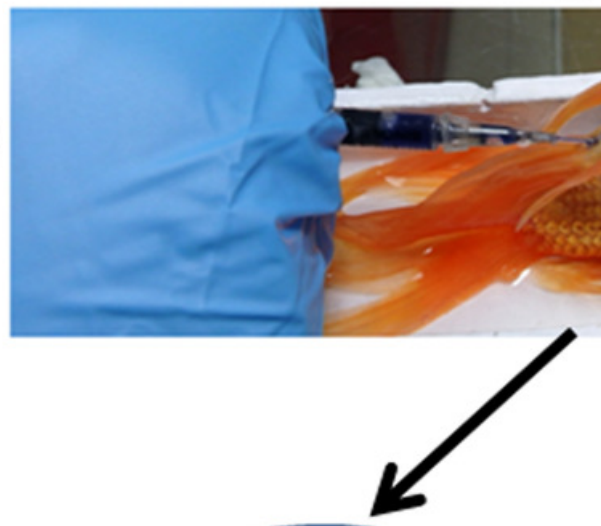

C

\section{Collection of sperm}

D

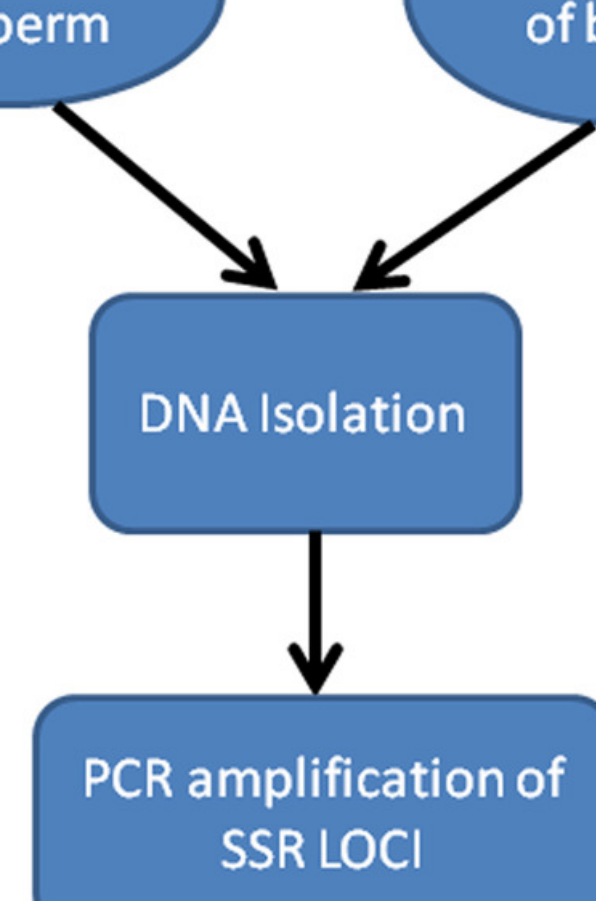

E SSR LOCI

F $180 \mathrm{bp} \longleftarrow$ ens

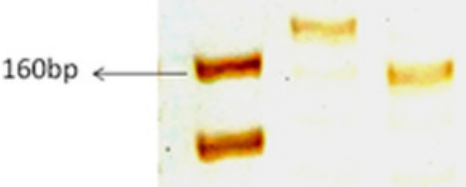




\section{Table $\mathbf{1}$ (on next page)}

Results of artificial fertilization.

The eggs derived from wild gravid $C$. auratus females with sperm from ten senescence $C$. auratus males ( $n=10$; transplanted with spermatogonia derived from pre-pubertal $C$. auratus donors) and control (crosses between sexually mature $C$. auratus males and females). Data presented are mean \pm SD. 


\begin{tabular}{|l|c|c|c|}
\hline Fertilization trail & $\begin{array}{l}\text { Eggs (n) from wild gravid } C . \\
\text { auratus females }\end{array}$ & $\begin{array}{l}\text { Fertilization rate } \\
(\mathrm{n} ; \%)\end{array}$ & $\begin{array}{l}\text { Hatching rate } \\
(\mathrm{n} ; \%)\end{array}$ \\
\hline $\begin{array}{l}\text { senescence C. auratus } \\
\text { males (n=10) }\end{array}$ & $476 \pm 107$ & $453 \pm 112$ & $432 \pm 109$ \\
\hline Control (n=3) & $503 \pm 99$ & $476 \pm 91$ & $460 \pm 95$ \\
\hline
\end{tabular}

1

2 


\section{Table 2 (on next page)}

Results of induced spawning.

The cross between senescence $C$. auratus males $(n=10$; transplanted with spermatogonia derived from pre-pubertal C. auratus donors) with wild gravid $C$. auratus females and a control (paired between sexually mature $C$. auratus males and females). Data presented are mean $\pm S D$. 


\begin{tabular}{|l|c|l|c|}
\hline Fertilization trail & $\begin{array}{l}\text { Total number of embryo } \\
\text { collected (n) }\end{array}$ & $\begin{array}{l}\text { Fertilization rate } \\
(\mathrm{n} ; \%)\end{array}$ & $\begin{array}{l}\text { Hatching rate } \\
\text { (n; \%) }\end{array}$ \\
\hline $\begin{array}{l}\text { senescence } C . \\
\text { auratus } \text { males } \\
\text { paired with gravid } \\
\text { C. auratus females } \\
(\mathrm{n}=10)\end{array}$ & $1068 \pm 271$ & $1046 \pm 273$ & $1026 \pm 277$ \\
\hline \begin{tabular}{l} 
Control $(\mathrm{n}=3)$ \\
\hline
\end{tabular} & $1091 \pm 140$ & $1068 \pm 128$ & $1047 \pm 127$ \\
\hline
\end{tabular}

1

2 


\section{Figure 8}

Schematic illustration of species-specific microsatellite loci J60* amplifying both senescent (recipient) and donor genomic DNA.

The species-specific microsatellite loci J60* (Yue and Orban, 2002) amplifying both senescent (recipient) and donor genomic DNA and visualization through silver staining. The two genotypes (A) senescent 166/166 and (B) donor 158/158) were electrophoretically resolved on polyacrylamide gel using Msp I digested pBR322 as ladder (M). 


\section{Senescent gDNA}<smiles>CCOC</smiles>

Donor gDNA

$$
160 * \text { locus amplified }
$$

Forward primer: 5'-CTGGCTGTCTGATCCTGCTGAT-3' Reverse primer: 3'-FGCCAGAGTITAAAAACCAGTCC-5'

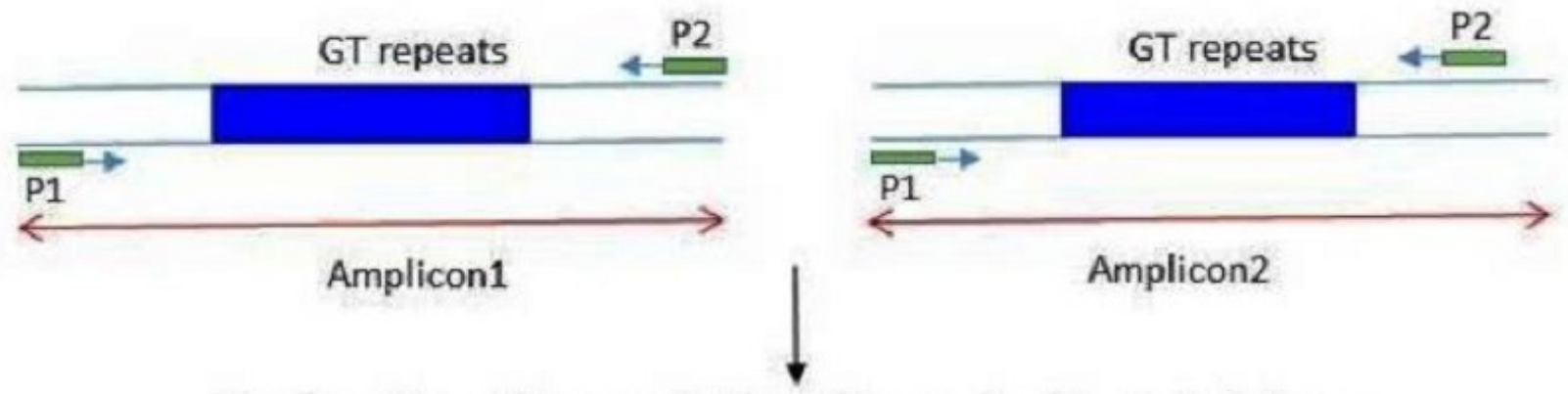

Electrophoretic resolution through silver staining

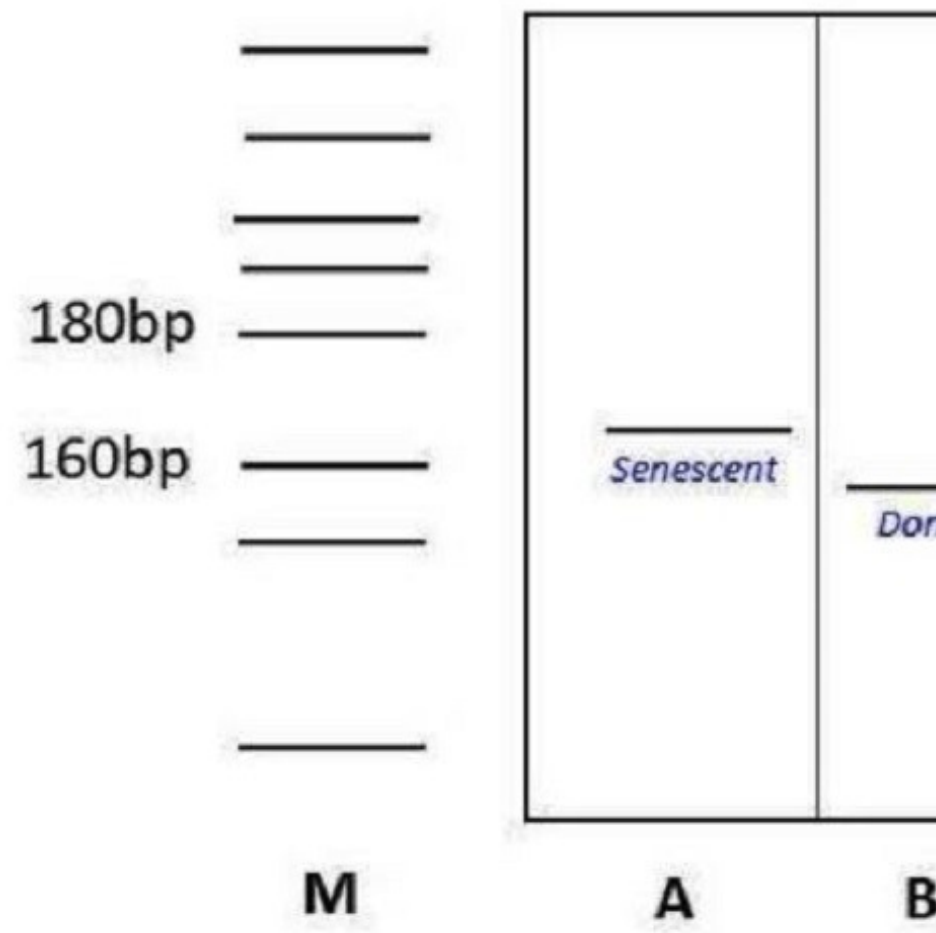

Genotypes

A: 166166

B: 158158 